\title{
Preservation of Motion at the Surgical Level after Minimally Invasive Posterior Cervical Foraminotomy
}

\author{
Young-Seok Lee, M.D., ${ }^{1}$ Young-Baeg Kim, M.D., Ph.D., ${ }^{2}$ Seung-Won Park, M.D., Ph.D., ${ }^{2}$ Dong-Ho Kang, M.D., Ph.D. \\ Department of Neurological Surgery, Gyeongsang National University School of Medicine, Jinju, Korea \\ Department of Neurosurgery, ${ }^{2}$ Chung-Ang University College of Medicine, Seoul, Korea
}

Objective : Although minimally invasive posterior cervical foraminotomy (MI-PCF) is an established approach for motion preservation, the outcomes are variable among patients. The objective of this study was to identify significant factors that influence motion preservation after MI-PCF.

Methods : Forty-eight patients who had undergone MI-PCF between 2004 and 2012 on a total of 70 levels were studied. Cervical parameters measured using plain radiography included C2-7 plumb line, C2-7 Cobb angle, T1 slope, thoracic outlet angle, neck tilt, and disc height before and 24 months after surgery. The ratios of the remaining facet joints after MI-PCF were calculated postoperatively using computed tomography. Changes in the distance between interspinous processes (DISP) and the segmental angle (SA) before and after surgery were also measured. We determined successful motion preservation with changes in DISP of $\leq 3$ $\mathrm{mm}$ and in $\mathrm{SA}$ of $\leq 2^{\circ}$.

Results : The differences in preoperative and postoperative DISP and SA after MI-PCF were $0.03 \pm 3.95 \mathrm{~mm}$ and $0.34 \pm 4.46^{\circ}$, respectively, fulfilling the criteria for successful motion preservation. However, the appropriate level of motion preservation is achieved in cases in which changes in preoperative and postoperative DISP and SA motions are 55.7 and $57.1 \%$, respectively. Based on preoperative and postoperative DISP, patients were divided into three groups, and the characteristics of each group were compared. Among these, the only statistically significant factor in motion preservation was preoperative disc height (Pearson's correlation coefficient $=0.658, p<0.001$ ). The optimal disc height for motion preservation in regard to DISP ranges from 4.18 to 7.08 $\mathrm{mm}$.

Conclusion : MI-PCF is a widely accepted approach for motion preservation, although desirable radiographic outcomes were only achieved in approximately half of the patients who had undergone the procedure. Since disc height appears to be a significant factor in motion preservation, surgeons should consider disc height before performing MI-PCF.

Key Words : Minimally invasive posterior cervical foraminotomy · Motion change $\cdot$ Motion preservation · Disc height.

- Received : September 9, 2015 •Revised : December 16, 2015 •Accepted : December 16, 2015

- Address for reprints : Young-Baeg Kim, M.D., Ph.D.

Department of Neurosurgery, Chung-Ang University College of Medicine, 102 Heukseok-ro, Dongjak-gu, Seoul 06973, Korea Tel : +82-2-6299-1607, Fax : +82-2-6299-2069, E-mail : ybkim1218@gmail.com

This is an Open Access article distributed under the terms of the Creative Commons Attribution Non-Commercial License (http://creativecommons.org/licenses/by-nc/4.0) which permits unrestricted non-commercial use, distribution, and reproduction in any medium, provided the original work is properly cited. 


\section{INTRODUCTION}

Cervical radiculopathy symptoms are common in cervical spine disease. Anterior cervical discectomy and fusion (ACDF) is commonly regarded as the gold standard for surgical treatment ${ }^{7}$. However, as a motion-preserving technique, posterior cervical foraminotomy (PCF) has also been widely used as an alternative to $\mathrm{ACDF}^{18}$. With advances in surgical instrumentation, tubular retractor-assisted minimally invasive posterior cervical foraminotomy (MI-PCF) in particular is advantageous for reducing blood loss, postoperative neck pain, and postoperative length of stay, compared to previous open techniques that were commonly used ${ }^{1,5,9)}$.

Studies comparing mean preoperative and postoperative results have shown that the greatest advantage of PCF is in postoperative motion preservation ${ }^{8,9)}$. However, Jagannathan et al. ${ }^{8)}$ reported that postoperative instability at the surgical level was observed in $4.9 \%$ of patients who had undergone PCF, and $25 \%$ of these subsequently underwent further cervical fu- sion. Therefore, this study aimed to investigate postoperative motion preservation after PCF, and to identify correlations with clinical outcomes and the factors that most influence motion preservation.

\section{MATERIALS AND METHODS}

\section{Study subjects}

This was a retrospective analytical study of a cohort of patients who had cervical radiculopathy and had undergone single- or two-level MI-PCF from 2004 to 2012. The patients had cervical radicular pain or weakness due to degenerative disease at C3 to $\mathrm{T} 1$, were diagnosed with foraminal stenosis or soft disc herniation, and had undergone surgery. Patients who had undergone surgery for trauma or tumors, or who had previously undergone other cervical operations, including anterior approach surgery, were excluded from this study. A total of 62 patients were selected. Of these, 48 with a minimum 2-year

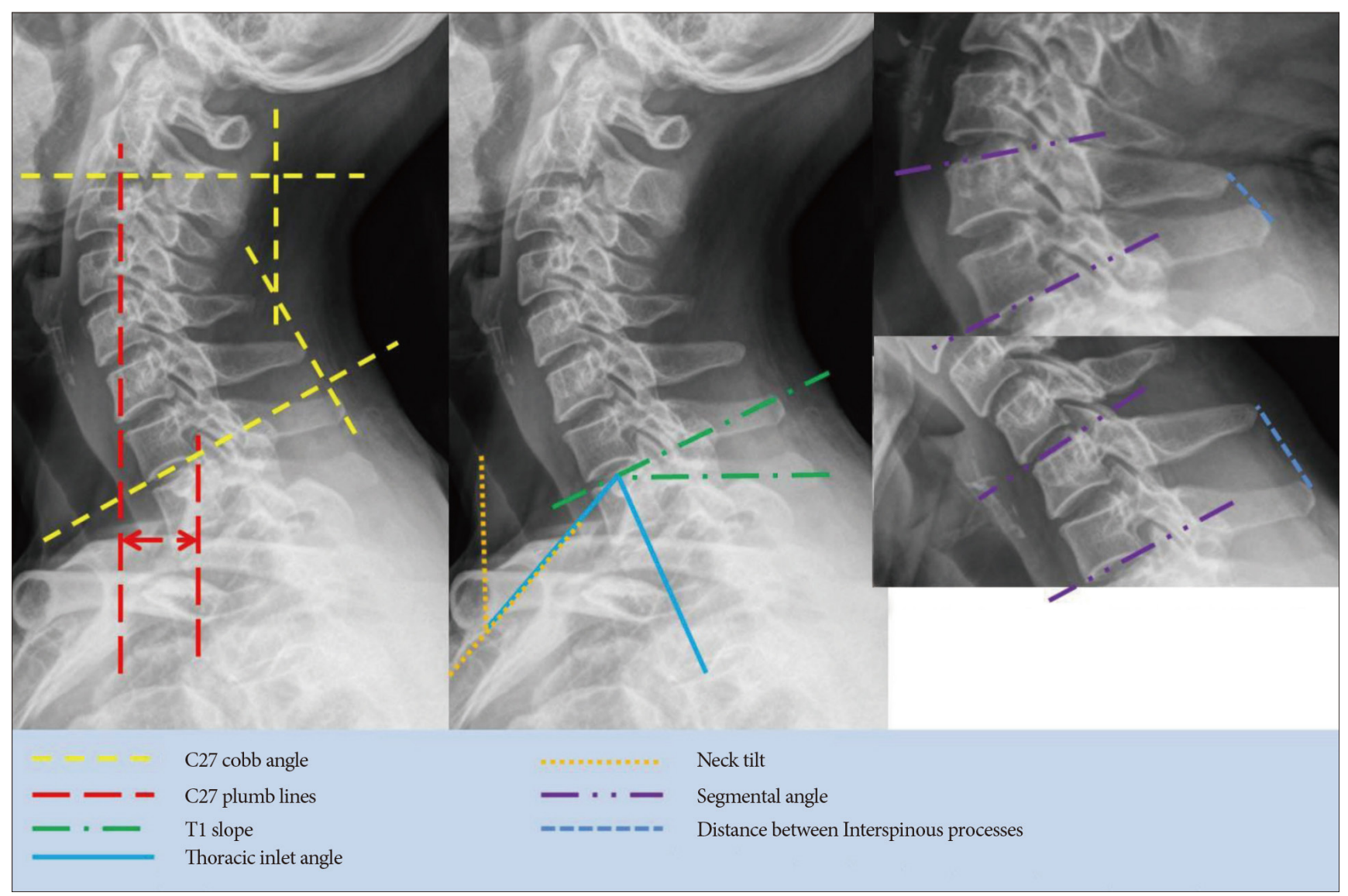

Fig. 1. Cervical parameters used to evaluate kyphotic change and motion preservation. 
follow-up were finally selected in order to evaluate motion outcomes. The mean follow-up duration was $43.19 \pm 17.19$ months.

\section{Surgical technique}

Following general anesthesia, patients were placed in the prone position with 3-point Mayfield fixation. C-arm fluoroscopy was utilized to confirm the surgical level. Using a minimally invasive system (METRx; Medtronics, Memphis, TN, USA), a tubular retractor was positioned on the surgical area with the lamina facet junction at its center. The lateral lamina

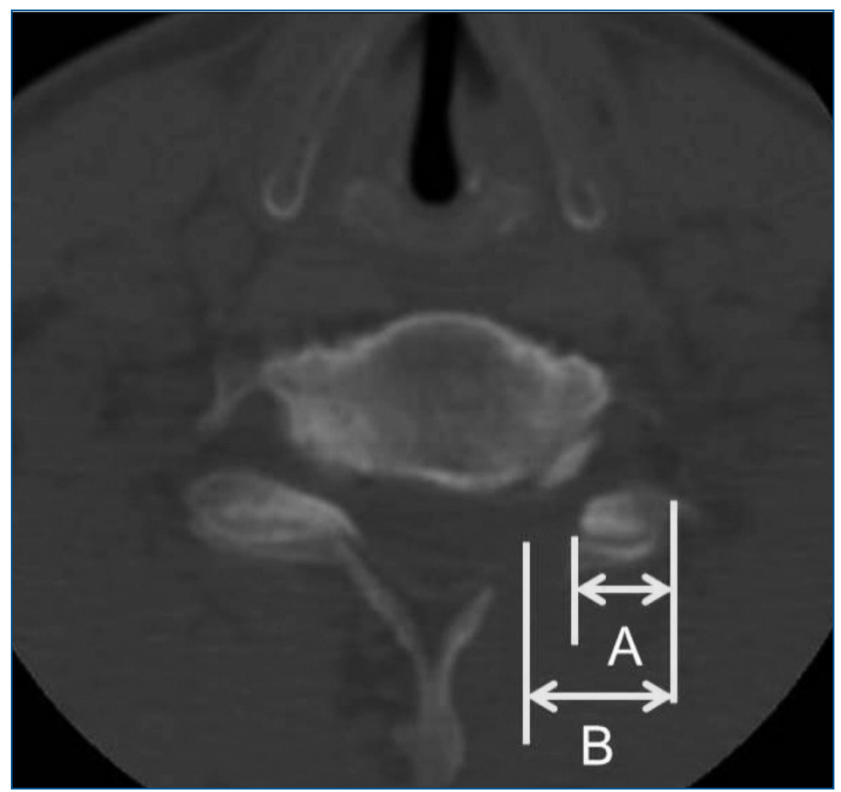

Fig. 2. Postoperative computed tomography shows the remnant of facet joint (A/B). and medial facet joint were carefully drilled to the cortical bone using a cutting burr, and foraminotomy was performed

Table 1. Patient characteristics

\begin{tabular}{lc}
\hline & Patient characteristics $(\mathbf{n}=\mathbf{4 8})$ \\
\hline Age & $55.13 \pm 9.47$ \\
Sex (M/F) & $35 / 13$ \\
Total levels & 70 \\
Diagnosis & \\
Foraminal stenosis & 25 \\
Soft disc herniation & 23 \\
OP level & \\
C4-5 & 6 \\
C5-6 & 25 \\
C6-7 & 31 \\
C7-T1 & 8 \\
Right/left & $23 / 25$ \\
VAS & \\
Preoperative & $7.64 \pm 0.68$ \\
Postoperative & $1.91 \pm 1.12$ \\
Modified Odom criteria & \\
Excellent & $32(66.7 \%)$ \\
Good & $12(25.0 \%)$ \\
Fair & $4(8.3 \%)$ \\
Poor & $0(0.0 \%)$ \\
Reoperation & $1(2.1 \%)$ \\
\hline Follow up duration (mo) & $43.19 \pm 17.19$ \\
\hline :ma & \\
\hline & \\
\hline
\end{tabular}

$\mathrm{M}$ : male, $\mathrm{F}$ : female, OP : operative, VAS : visual analog scale, mo : month

Table 2. Radiologic cervical parameters of patients who had undergone minimally invasive posterior cervical foraminotomy

\begin{tabular}{|c|c|c|c|}
\hline Cervical parameter & Preoperative & Postoperative & $p$-value \\
\hline Disc height (mm) & $5.64 \pm 1.26$ & $5.50 \pm 1.20$ & 0.066 \\
\hline T1 slope $\left(^{\circ}\right)$ & $20.93 \pm 5.99$ & $21.45 \pm 7.31$ & 0.594 \\
\hline Thoracic inlet angle $\left(^{\circ}\right)$ & $71.83 \pm 10.79$ & $70.82 \pm 8.46$ & 0.479 \\
\hline Neck tilt $\left(^{\circ}\right)$ & $50.80 \pm 10.41$ & $49.37 \pm 7.81$ & 0.282 \\
\hline C2-7 plumb line $(\mathrm{mm})$ & $20.68 \pm 10.17$ & $21.84 \pm 11.34$ & 0.511 \\
\hline C2-7 cobb angle $\left(^{\circ}\right)$ & $7.87 \pm 10.88$ & $7.74 \pm 10.82$ & 0.921 \\
\hline Segmental angle $\left(^{\circ}\right)$ & $7.75 \pm 5.44$ & $8.09 \pm 5.80$ & 0.524 \\
\hline Distance between interspinous processes (mm) & $5.58 \pm 3.62$ & $5.61 \pm 4.81$ & 0.958 \\
\hline Remnant of facet joint (\%) & & $65.04 \pm 0.12$ & \\
\hline Pre-post segmental angle $\left(^{\circ}\right)$ & & $0.34 \pm 4.46$ & \\
\hline Pre-post interspinous process (mm) & & $0.03 \pm 3.95$ & \\
\hline
\end{tabular}

Pre : preoperative, Post : postoperative 
J Korean Neurosurg Soc 60 | July 2017

Table 3. Demographic and preoperative and postoperative data for each group according to motion change in patients who had undergone minimally invasive posterior cervical foraminotomy

\begin{tabular}{|c|c|c|c|c|}
\hline & Group A $(n=16)$ & Group B $(n=40)$ & Group C ( $n=14)$ & $p$-value \\
\hline Age & $61.18 \pm 5.86$ & $52.42 \pm 9.95$ & $56.11 \pm 8.52$ & 0.029 \\
\hline $\operatorname{Sex}(M: F)$ & $10: 6$ & $26: 9$ & $12: 1$ & 0.181 \\
\hline OP level & & & & 0.914 \\
\hline C4-5 & 1 & 4 & 1 & \\
\hline$C 5-6$ & 5 & 16 & 4 & \\
\hline C6-7 & 8 & 15 & 8 & \\
\hline $\mathrm{C} 7-\mathrm{T} 1$ & 2 & 5 & 1 & \\
\hline Right: left & $7: 3$ & $12: 16$ & $3: 6$ & 0.528 \\
\hline \multicolumn{5}{|l|}{ VAS } \\
\hline Pre & $7.40 \pm 0.70$ & $7.81 \pm 0.63$ & $7.44 \pm 0.73$ & \\
\hline Post & $2.20 \pm 1.55$ & $1.85 \pm 0.99$ & $1.78 \pm 0.97$ & \\
\hline Modified Odom criteria & & & & 0.995 \\
\hline Excellent & 7 & 19 & 6 & \\
\hline Good & 3 & 7 & 2 & \\
\hline Fair & 1 & 2 & 1 & \\
\hline Poor & 0 & 0 & 0 & \\
\hline \multicolumn{5}{|l|}{ Disc height $(\mathrm{mm})^{*}$} \\
\hline Pre & $4.59 \pm 0.90$ & $5.60 \pm 1.05$ & $6.97 \pm 0.93$ & $<0.001$ \\
\hline Post & $4.57 \pm 0.85$ & $5.60 \pm 10.5$ & $6.29 \pm 1.30$ & $<0.000$ \\
\hline \multicolumn{5}{|l|}{ T1 slope $\left(^{\circ}\right)$} \\
\hline Pre & $17.70 \pm 4.55$ & $21.54 \pm 5.76$ & $22.14 \pm 7.29$ & 0.102 \\
\hline Post & $18.46 \pm 8.26$ & $22.07 \pm 7.44$ & $23.01 \pm 5.05$ & 0.527 \\
\hline \multicolumn{5}{|l|}{ Thoracic inlet angle $\left({ }^{\circ}\right)$} \\
\hline Pre & $73.92 \pm 11.90$ & $70.66 \pm 10.65$ & $73.08 \pm 9.28$ & 0.591 \\
\hline Post & $70.49 \pm 8.58$ & $69.82 \pm 8.84$ & $74.72 \pm 6.56$ & 0.332 \\
\hline \multicolumn{5}{|l|}{ Neck tiltt $\left(^{\circ}\right)$} \\
\hline Pre & $56.22 \pm 12.30$ & $49.12 \pm 8.20$ & $50.93 \pm 12.52$ & 0.283 \\
\hline Post & $52.02 \pm 7.20$ & $47.75 \pm 7.80$ & $51.71 \pm 8.05$ & 0.318 \\
\hline \multicolumn{5}{|l|}{ C2-7 plump line $(\mathrm{mm})$} \\
\hline Pre & $18.60 \pm 2.69$ & $22.65 .2 \pm 10.72$ & $18.93 \pm 2.56$ & 0.15 \\
\hline Post & $15.75 \pm 9.44$ & $23.12 \pm 11.87$ & $24.96 \pm 9.90$ & 0.097 \\
\hline \multicolumn{5}{|l|}{ C2-7 Cobb angle $\left(^{\circ}\right)$} \\
\hline Pre & $8.23 \pm 8.33$ & $8.23 \pm 11.38$ & $8.27 \pm 13.22$ & 1 \\
\hline Post & $5.90 \pm 9.27$ & $8.07 \pm 11.30$ & $8.87 \pm 11.98$ & 0.856 \\
\hline Remnant of facet joint (\%) & $0.62 \pm 0.11$ & $0.68 \pm 0.13$ & $0.61 \pm 0.12$ & 0.131 \\
\hline \multicolumn{5}{|l|}{ Segmental angle $\left(^{\circ}\right)$} \\
\hline Pre & $8.48 \pm 4.66$ & $9.66 \pm 5.87$ & $7.19 \pm 5.27$ & 0.805 \\
\hline Post & $6.12 \pm 5.27$ & $7.85 \pm 5.93$ & $11.02 \pm 5.03$ & 0.061 \\
\hline \multicolumn{5}{|l|}{ Interspinous process (mm) } \\
\hline $\operatorname{Pre}^{*}$ & $6.67 \pm 3.55$ & $5.60 \pm 3.76$ & $4.30 \pm 3.06$ & 0.205 \\
\hline Post & $1.83 \pm 2.96$ & $5.55 \pm 4.58$ & $10.07 \pm 3.20$ & $<0.001$ \\
\hline
\end{tabular}

*Statistically significant difference. $M$ : male, F : female, OP : operative, Pre : preoperative, Post : postoperative, VAS : visual analog scale 
using a curette to minimize bleeding. To prevent postoperative instability, no more than $50 \%$ of the facet joint was removed. Disc fragments are commonly found at the axillary nerve root, and any fragments between the medial dura and the root were carefully removed using a hook.

\section{Radiological evaluation}

To evaluate kyphotic change, we measured C2-7 plumb line, $\mathrm{C} 2-7$ Cobb angle, $\mathrm{T} 1$ slope, thoracic outlet angle, and neck tilt; to evaluate motion preservation, we measured disc height, distance between interspinous processes (DISP) and segmental angle (SA) changes; all measurements were made before and 24 months after surgery (Fig. 1). The ratios of the remaining facet joints after MI-PCF were calculated using computed tomography (Fig. 2).

C2-7 Cobb angle, C2-7 plumb line, T1 slope, thoracic inlet angle, neck tilt, and disc height were measured using plain radiography in the neutral position. C2-7 Cobb angle was defined as the angle between the lower edge of the vertebral body of $\mathrm{C} 2$ and the upper edge of the vertebral body of $\mathrm{C}$. C2-7 plumb line was defined as the distance between two lines dropped vertically from the center of $\mathrm{C} 2$ and from the posterior superior aspect of $\mathrm{C} 7^{17)}$. T1 slope was defined as the angle between the horizontal plane and a line parallel to the superior T1 endplate. The thoracic inlet angle was defined as the angle between a line originating from the center of and perpendicular to the $\mathrm{T} 1$ endplate and a line from the center of the T1 endplate to the upper end of the sternum. Neck tilt was defined as an angle between 2 lines originating from the upper end of the sternum, one of which is vertical and the other connecting the center of the $\mathrm{T} 1$ endplate ${ }^{11)}$.

Disc height was determined by measuring the distance between the midpoints of the upper and lower edges of the vertebral body of the surgical level on a neutral lateral radiograph. SA was determined by measuring the Cobb angle from the upper endplate of the upper vertebral body to the lower endplate of the lower vertebral body. DISP was defined as the distance between the adjacent spinous processes at the surgical level on flexion/extension radiographs.

Preservation of motion referred to a postoperative difference of less than $3 \mathrm{~mm}$ DISP and $2^{\circ} \mathrm{SA}$ in flexion/extension plain radiographs. A difference of more than $3 \mathrm{~mm}$ DISP and $2^{\circ}$ SA was defined as instability ${ }^{8}$.

A preoperative and postoperative DISP gap decrease of more than $3 \mathrm{~mm}$ was classified into group A, a gap less than 3 $\mathrm{mm}$ was classified into group $\mathrm{B}$, and a gap increase of more than $3 \mathrm{~mm}$ was classified into group C.

The images were saved in Digital Imaging and Communications in Medicine (DICOM) format on the picture archiving and communication system. The C-spine images were enlarged by $100 \%$ before assessment. The radiographic measurements and evaluations were initially performed by one surgeon, and independently reviewed and confirmed by two other surgeons.

\section{Clinical evaluation}

For clinical outcome, preoperative and the latest postoperative visual analog scale (VAS) scores were compared, and the last postoperative clinical outcome was evaluated using the modified Odom criteria.

\section{Statistical analysis}

For the three groups, analysis of variance, the Kruskal-Wallis $\mathrm{H}$ test, and the chi-square test were used for comparison of patient characteristics, and the degree of change in preopera-

Table 4. Correlation between pre-postoperative motion change and preoperative cervical parameters

\begin{tabular}{lccccc}
\hline & \multicolumn{2}{c}{ Best pre-post distance between interspinous processes } & & \multicolumn{2}{c}{ Best pre-post segmental angle } \\
\cline { 2 - 3 } \cline { 5 - 6 } & \multicolumn{1}{c}{ Coefficient of correlation } & $\boldsymbol{p}$-value & & Coefficient of correlation & $p$-value \\
\hline Disc height* & 0.658 & $<0.001$ & 0.258 & 0.017 \\
T1 slope & 0.185 & 0.207 & 0.136 & 0.356 \\
Neck tilt & -0.202 & 0.168 & -0.071 & 0.634 \\
Thoracic inlet angle & -0.021 & 0.886 & -0.013 & 0.933 \\
C2-7 plumb line & 0.237 & 0.106 & 0.19 & 0.196 \\
C2-7 Cobb angle & -0.044 & 0.765 & -0.073 & 0.624 \\
\hline
\end{tabular}

*Statistically significant difference. Pre : preoperative, Post : postoperative 

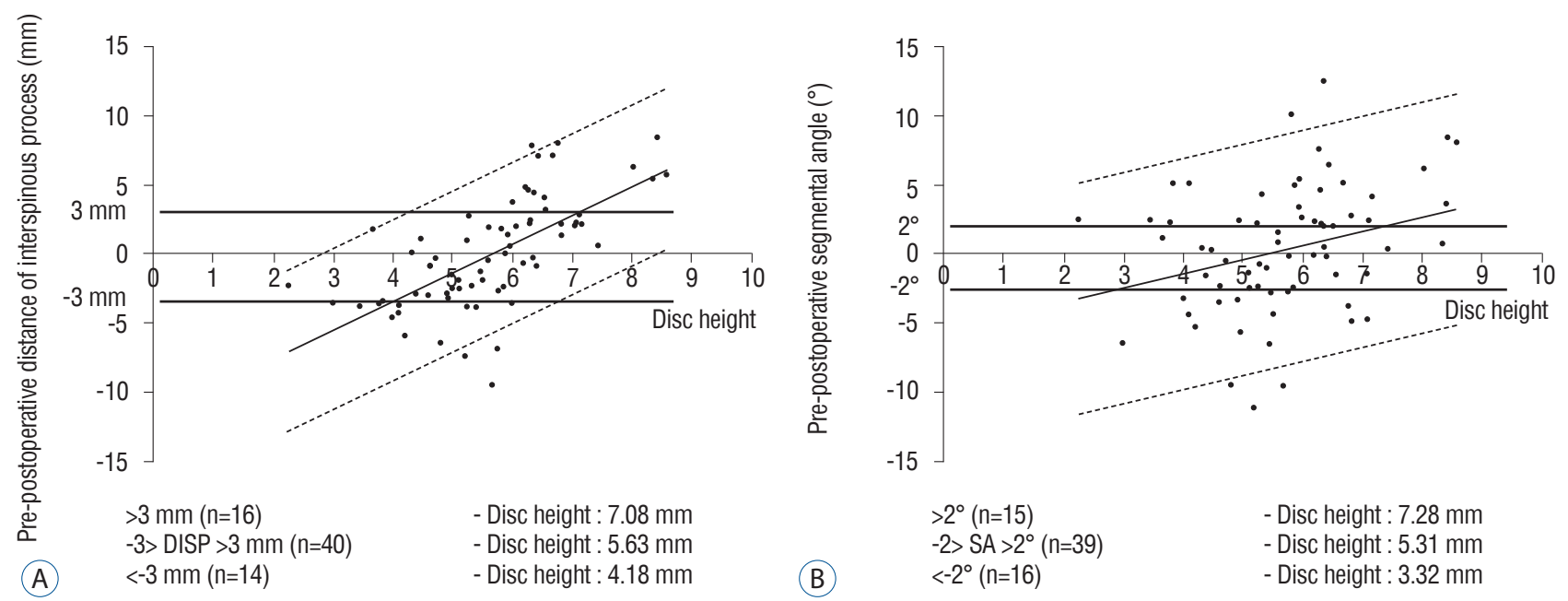

Fig. 3. Correlation between pre-postoperative motion change and disc heights. Correlation coefficient $(r)$ is 0.658 for pre-postoperative distance between interspinous processes $(A)(p<0.001)$ and 0.258 for pre-postoperative segmental angle (B) $(p=0.017)$.

tive and postoperative radiological outcomes was compared using the paired t-test. The Pearson correlation coefficient test was used to analyze the relationship between cervical parameters and pre/postoperative motion change (SA and DISP). $p$ values of $<0.05$ were considered statistically significant. Statistical analyses were performed using SPSS software version 18.0 (SPSS Inc., Chicago, IL, USA).

\section{RESULTS}

Patient characteristics and clinical outcomes are summarized in Table 1. The mean age of the patients was $55.13 \pm 9.47$, and there were 25 male and 13 female patients; $52.1 \%$ had foraminal stenosis and $47.9 \%$ had soft disc herniation. Surgery was mostly performed on C5-6 and C6-7, with a similar ratio of left to right sides. The VAS score decreased from 7.64 before surgery to 1.91 after surgery, showing more than a "good" clinical improvement at $91.7 \%$ in the modified Odom criteria.

Preoperative and last postoperative cervical parameters were compared (Table 2). Disc height, T1 slope, thoracic inlet angle, neck tilt, C2-7 plumb line, and C2-7 Cobb angle did not reveal a statistically significant difference. Therefore, preoperative cervical parameters were well maintained postoperatively. The last SA changed by $0.34 \pm 4.46^{\circ}$, from $7.75 \pm 5.44^{\circ}$ before surgery to $8.09 \pm 5.80^{\circ}$, and DISP changed by $0.03 \pm 3.95 \mathrm{~mm}$, from $5.58 \pm 3.62 \mathrm{~mm}$ to $5.61 \pm 4.81 \mathrm{~mm}$, also indicating no statistical significance. The proportion of the facet joint remain- ing after MI-PCF was $65.04 \pm 0.12 \%$, and there were no cases in which more than $50 \%$ of the facet joint was removed.

Based on preoperative and postoperative DISP, patients were divided into groups $\mathrm{A}, \mathrm{B}$, and $\mathrm{C}$, and the characteristics of each group were compared (Table 3 ). Statistically significant differences between the three groups were found only for preoperative and postoperative disc height. Moreover, in a comparison between preoperative and postoperative SA and DISP changes using the Pearson correlation coefficient, only disc height showed a statistically significant correlation. Values for preoperative and postoperative DISP change and disc height were $r=0.658$ and $p<0.001$, and for SA change and disc height were $\mathrm{r}=0.258$ and $p=0.017$ (Table 4). The optimal disc height for motion preservation was $5.63 \mathrm{~mm}(4.18-7.08 \mathrm{~mm})$ based on DISP, and $5.31 \mathrm{~mm}(3.32-7.28 \mathrm{~mm})$ based on SA (Fig. 3).

\section{DISCUSSION}

PCF was first introduced for cervical radiculopathy by Scoville in 1966, and has been used with $\mathrm{ACDF}^{18)}$. Along with PCF, MI-PCF has gradually evolved since 2000, and now shows results similar to those of open $\mathrm{PCF}^{9,16,19)}$. Short- and long-term postoperative outcomes for pain, complications, and quality of life for PCF are similar to $\mathrm{ACDF}^{7,12,20)}$. In addition, PCF possesses the advantages of motion preservation, potential avoidance of adjacent segment disease, and reduc- 
tion in morbidity associated with a ventral approach and pseudarthrosis. PCF costs $52.7 \%$ less than $\mathrm{ACDF}^{14)}$. In the present study, MI-PCF showed superior clinical outcomes at $91.7 \%$, and overall motion was well preserved without changes in postoperative cervical parameters, including disc height, $\mathrm{T} 1$ slope, thoracic inlet angle, neck tilt, $\mathrm{C} 2-7$ plumb line, and C2-7 Cobb angle. This indicates that MI-PCF adequately preserves motion.

However, Jagannathan et al. ${ }^{8}$ reported that dynamic images showed postoperative instability in 8 of 161 patients (4.9\%), one of whom required cervical fusion. Moreover, the reoperation rate after PCF was reported as $5.3-9.9 \% \%^{3,12,19)}$. The present study showed a $2.1 \%$ reoperation rate. However, only $57.1 \%$ showed ideal motion preservation postoperatively. Moreover, when changes in segmental motion were measured using preoperative and postoperative SA and DISP, cervical parameters and clinical outcomes did not show any differences; only a statistically significant difference in disc height was observed. This indicates that a small size of disc height tends to decrease postoperative motion, while a large size of disc height tends to increase motion.

This study confirmed that a disc height of $5.63 \mathrm{~mm}$ would show optimal motion preservation after MI-PCF. Disc heights of more than $7.08 \mathrm{~mm}$ or less than $4.18 \mathrm{~mm}$ show different postoperative segmental motion and may be the reason why the adjacent segment is affected. This process mimics age-related degenerative change, which is believed to be caused by disc height and segmental motion decreases ${ }^{19}$. However, both motion decreases and increases were observed postoperatively, and there was a statistically significant correlation between disc height and segment motion. From a biomechanical perspective, PCF preserves normal segmental motion compared to ACDF, and is therefore predicted to reduce the onset of adjacent segment disease ${ }^{4,13,15}$. However, the mean rate of reoperation for clinical adjacent segment disease in ACDF was reported as $0.8 \%$ per year ${ }^{10)}$, and $0.9 \%$ per year following MI$\mathrm{PCF}^{19)}$, indicating no difference in the onset of clinical adjacent segment disease. In other words, although adjacent segment disease could be due to age-related disc degeneration, segment motion preservation after PCF was seen in only $51.7 \%$ of cases, which may influence the onset of clinical adjacent segment disease.

Postoperative kyphosis is a radiographic complication that commonly occurs after a posterior cervical approach. Patients with postoperative kyphosis also show a lower quality of life after surgery ${ }^{8}$. Patient age, postoperative diagnosis, aggressiveness of posterior resection, and previous posterior surgery are known to be risk factors for post-laminectomy kyphosis; in particular, the extent of facetectomy resection is a well-known risk factor ${ }^{2,211}$. In the present study, we attempted to maintain the extent of facetectomy resection at less than $50 \%$, and the proportion of the facet joint remaining was $65.04 \pm 0.12 \%$. With single- or two-level MI-PCF, overall segmental angle and C2-7 Cobb angle did not show a correlation with postoperative kyphosis; according to motion changes, no group exhibited differences in postoperative kyphosis rates.

During the minimum 5-year follow up after cervical laminoplasty, range of motion loss at 18 months postoperatively reportedly decreased to $38.5 \%$ in a time-dependent manner, but remained constant after 18 months ${ }^{6}$. Unlike cervical laminoplasty, PCF did not show loss in range of motion. Well-preserved posterior tension bands may contribute to reduced changes in motion. Thus, cervical parameters in addition to disc height are well preserved, with no differences in clinical outcomes.

The major limitation of this study is the absence of a control group. This is also a retrospective study. In addition, although cervical motion was measured in dynamic views, the extent of the influence of pain on motion and multidirectional movement such as rotation were not considered. Moreover, a small number of subjects was included in the study, so the data showed a large standard deviation. Therefore, prospective studies involving larger numbers of patients and longer followups are necessary to accurately measure motion after PCF.

\section{CONCLUSION}

MI-PCF is a useful surgical method for cervical radiculopathy, with favorable preservation of cervical parameters, superior clinical outcomes, and low reoperation rates. However, only $55.7 \%$ of patients showed proper motion preservation after MI-PCF. Those with a preoperative disc height of 4.18-7.08 $\mathrm{mm}$ showed optimal motion preservation; thus, preoperative disc height measurement can predict preservation of motion after MI-PCF. 


\section{References}

1. Adamson TE : Microendoscopic posterior cervical laminoforaminotomy for unilateral radiculopathy: results of a new technique in 100 cases. J Neurosurg 95(1 Suppl): 51-57, 2001

2. Albert TJ, Vacarro A : Postlaminectomy kyphosis. Spine (Phila Pa 1976) $23: 2738-2745,1998$

3. Bydon M, Mathios D, Macki M, de la Garza-Ramos R, Sciubba DM, Witham TF, et al. : Long-term patient outcomes after posterior cervical foraminotomy: an analysis of 151 cases. J Neurosurg Spine 21 : 727731, 2014

4. Eck JC, Humphreys SC, Lim TH, Jeong ST, Kim JG, Hodges SD, et al. : Biomechanical study on the effect of cervical spine fusion on adjacentlevel intradiscal pressure and segmental motion. Spine (Phila Pa 1976) 27 : 2431-2434, 2002

5. Fessler RG, Khoo LT : Minimally invasive cervical microendoscopic foraminotomy: an initial clinical experience. Neurosurgery 51(5 Suppl) : S37-S45, 2002

6. Hyun SJ, Riew KD, Rhim SC : Range of motion loss after cervical laminoplasty: a prospective study with minimum 5 -year follow-up data. Spine J 13 : 384-390, 2013

7. Jacobs W, Willems PC, Kruyt M, van Limbeek J, Anderson PG, Pavlov P, et al. : Systematic review of anterior interbody fusion techniques for single- and double-level cervical degenerative disc disease. Spine (Phila Pa 1976) 36 : E950-E960, 2011

8. Jagannathan J, Sherman JH, Szabo T, Shaffrey Cl, Jane JA : The posterior cervical foraminotomy in the treatment of cervical disc/osteophyte disease: a single-surgeon experience with a minimum of 5 years' clinical and radiographic follow-up. J Neurosurg Spine 10 : 347-356, 2009

9. Kim KT, Kim YB : Comparison between open procedure and tubular retractor assisted procedure for cervical radiculopathy: results of a randomized controlled study. J Korean Med Sci 24 : 649-653, 2009

10. Lawrence BD, Hilibrand AS, Brodt ED, Dettori JR, Brodke DS : Predicting the risk of adjacent segment pathology in the cervical spine: a systematic review. Spine (Phila Pa 1976) 37(22 Suppl) : S52-S64, 2012
11. Lee SH, Kim KT, Seo EM, Suk KS, Kwack YH, Son ES : The influence of thoracic inlet alignment on the craniocervical sagittal balance in asymptomatic adults. J Spinal Disord Tech 25 : E41-E47, 2012

12. Lubelski $D$, Healy AT, Silverstein MP, Abdullah KG, Thompson NR, Riew $K D$, et al. : Reoperation rates after anterior cervical discectomy and fusion versus posterior cervical foraminotomy: a propensity-matched analysis. Spine J 15 : 1277-1283, 2015

13. Maiman DJ, Kumaresan S, Yoganandan N, Pintar FA : Biomechanical effect of anterior cervical spine fusion on adjacent segments. Biomed Mater Eng 9 : 27-38, 1999

14. Mansfield HE, Canar WJ, Gerard CS, O'Toole JE : Single-level anterior cervical discectomy and fusion versus minimally invasive posterior cervical foraminotomy for patients with cervical radiculopathy: a cost analysis. Neurosurg Focus 37 : E9, 2014

15. Matsumoto M, Okada E, Ichihara D, Watanabe K, Chiba K, Toyama Y, et al. : Anterior cervical decompression and fusion accelerates adjacent segment degeneration: comparison with asymptomatic volunteers in a ten-year magnetic resonance imaging follow-up study. Spine (Phila Pa 1976) 35 : 36-43, 2010

16. McAnany SJ, Kim JS, Overley SC, Baird EO, Anderson PA, Qureshi SA : A meta-analysis of cervical foraminotomy: open versus minimally-invasive techniques. Spine J $15: 849-856,2015$

17. Scheer JK, Tang JA, Smith JS, Acosta FL Jr, Protopsaltis TS, Blondel B, et al. : Cervical spine alignment, sagittal deformity, and clinical implications: a review. J Neurosurg Spine 19 : 141-159, 2013

18. Scoville WB : Types of cervical disk lesions and their surgical approaches. JAMA $196:$ 479-481, 1966

19. Skovrlj B, Gologorsky Y, Haque R, Fessler RG, Qureshi SA : Complications, outcomes, and need for fusion after minimally invasive posterior cervical foraminotomy and microdiscectomy. Spine J 14 : 2405-2411, 2014

20. Wang TY, Lubelski D, Abdullah KG, Steinmetz MP, Benzel EC, Mroz TE : Rates of anterior cervical discectomy and fusion after initial posterior cervical foraminotomy. Spine J 15 : 971-976, 2015

21. Zdeblick TA, Zou D, Warden KE, McCabe R, Kunz D, Vanderby R : Cervical stability after foraminotomy. A biomechanical in vitro analysis. J Bone Joint Surg Am 74 : 22-27, 1992 